\title{
Evaluating the Cultural Anthropology of Artefacts of Computer Mediated Communication: A Case of Law Enforcement Agencies
}

\author{
ChukwuNonso H. Nwokoye* \\ Nigerian Correctional Service \\ chinonsonwokoye@gmail.com \\ Njideka Mbeledogu \\ Faculty of Physical Sciences, Nnamdi Azikiwe University Awka, Nigeria \\ njidembeledogu@yahoo.com \\ Chikwe Umeugoji \\ Faculty of Physical Sciences, Nnamdi Azikiwe University Awka, Nigeria \\ Chikw@live.ca
}

Received: 10/Mar/2020 Revised: 24/Jun/2021 Accepted: 06/Jul/2021

\begin{abstract}
The renowned orientations of cultural models proposed by Hall and Hofstede has been the subject of criticisms. This is due to the weak, inflexible and old-fashioned nature of some designs resulting from them. In addition, is the ever-changing, formless and undefined nature of culture and globalization. Consequently, these vituperations have resulted in better clarifications when assessing the cultural anthropology of websites. Based on these later clarifications and other additions, we seek to evaluate the cultural heuristics of websites owned by agencies of the Nigerian government. Note that this is verily necessary because older models did not include Africa in their analyses. Specifically, we employed the online survey method by distributing questionnaires to different groups of experts drawn from the various regions of Nigeria. The experts employed methods such as manual inspection and use of automated tools to reach conclusions. Afterwards, the results were assembled and using the choice of a simple majority, we decided whether a design parameter is either high or low context. Findings show that websites developers tend to favor low context styles when choosing design parameters. The paper attempts to situate Africa in Hall's continuum; therein, Nigeria (Africa) may fall within French Canadian and Scandinavian and/or within Latin and Scandinavian for the left hand and right hand side diagram respectively. In future, we would study the cultural anthropology of African websites employing the design parameters proposed by Alexander, et al.
\end{abstract}

Keywords: Website; Culture Contexts; E-governance; Cultural Anthropology; Human Computer Interaction.

\section{1- Introduction}

The burgeoning use of the internet as well as the flourishing number of application developers has productively influenced business organizations in exhibiting and fulfilling their goals on the World Wide Web using websites. Most marketing industries quickly adopted this approach as it offered them an ideal platform to present their products and services to local and foreign customers. Not long ago, with the exploration and incorporation of multimedia forms such as flash, sound and video, web site design have moved beyond simple static text-based formats to dynamic and interactive approaches. By that means, encouraging a towering measure of standard in terms of superior interaction using the web. Nevertheless, to construct a cross-culturally adequate website from a marketing viewpoint, web developers mostly addresses the concerns that border a "culture-specific color connotations, preferences in layout, animation, sounds, and other effects that are characteristic of today's generation of Web sites" [1]. This perspective is also sustained to a huge length for websites of egovernment which fundamentally endeavor to supply a citizen-centric device for effectual delivery of service by government agencies. Investigating the user conduct and temperament of design constituents is to extract most of the hints a developer should utilize in order to make certain that the "values and behavior indoctrinated through cultural influences are reflected in design practices" [1].

Researchers at some quarters has criticized the renowned orientations of cultural models proposed by Hall [2] and Hofstede [3] due to the inflexible and old-fashioned nature of some designs originating from them. This is hugely due to the fact that culture and globalization are ever-changing, formless [4] and undefined by geographical boundaries existent in-between nations. Notwithstanding the vituperations, empirical studies on e-government websites are still based on the conceptions of Hall and Hofstede. Several variables were proposed by Hall to support the placement of cultures in a continuum that spans bi- 
directionally from high-content/low-content to the lowcontext/high-content. These variables include Nonverbal communication, Directness vs Indirectness, Time perception (monochronic vs polychronic) and Message speed. In summary, "the classifications of Hall [2] for either high or low context culture is mostly based on the degree to which meaning comes from the words that are being exchanged in a communication or from the setting (context) in which the communication is taking place".

Hofstede also proposed cultural variables which include the dimensions of Collectivism versus Individualism. Culture differences have impacted the evolution and the utilization of information and communication technologies. Myers and Tan [5] maintained that, "...by far the majority of studies concerned with various cultural aspects of the development, implementation, use and management of IT have relied on Hofstede's model of national culture". Even though cultural anthropology has been applied to management and advertising, this study presents its application to one of the forms of computer mediated communication. Note that cultural anthropology is a field that investigates cultures of humans, their belief systems, customs, principles, objectives, technologies, economies and other dimensions of social and cognitive organization. Though culture context analyses are essential in defining some aspects of a society, a nation, a culture or even a continent, it is not easy to say if a country is either high or low-context in nature. Depending on the values and attributes of a particular society, people can operate at both ends, in the middle or at one end of the continuum. However, it is clear from Fig. 1 below, that Africa (Nigeria) is absent in the cultural models of Hall [2].

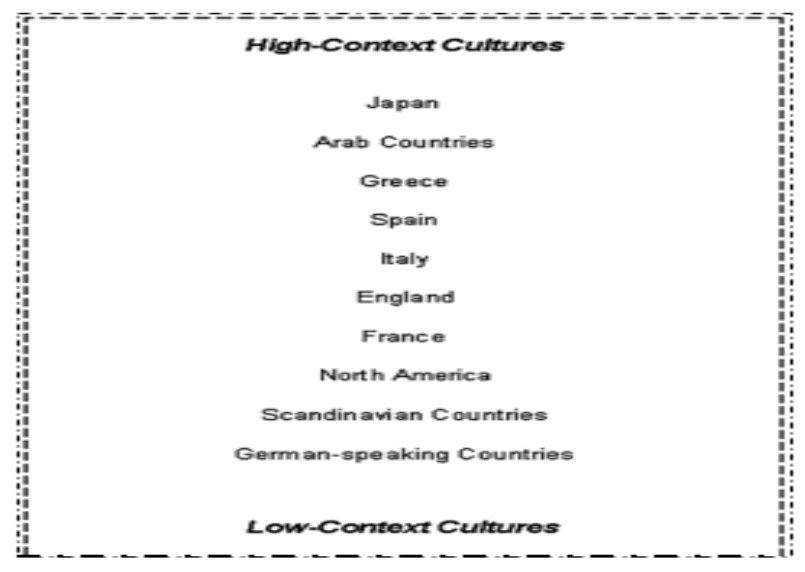

Fig. 1 High/Low Context Culture [2]

Consequently, in the light of the above, this study is aimed at evaluating the culture context dimensions of websites of law enforcement e-government agencies (LEEGA) in Nigeria using online survey method. This is to situate Africa (and Nigeria) in Hall's bidirectional continuum for analyzing high or low context cultures. The government agencies include Nigeria Air Force (NAF), Nigeria Navy (NN), Nigeria Army (NA), Nigeria Police Force (NPF), Nigeria Prisons Service (NPS), Nigeria Immigration Service (NIS), Nigeria Security and Civil Defense Corps (NSCDC), Nigeria Customs Service (NCS), Federal Road Safety Corps (FRSC), Federal Fire Service (FFS), Defense Intelligence Agency (DIA), National Drug Law Enforcement Agency (NDLEA), Independent Corrupt Practices and Other Related Offences Commission (ICPC), Economic and Financial Crimes Commission (EFCC). Thirteen (13) design parameters to be used for the analyses include Animation (Multiple use of images/banners) (AIB), Promotion of values (PV), Individuals separate or together with the product (IS), Level of transparency (LT), Navigation (linear vs parallel) (NLP), Multiple use of links (ML), Sell approach (hard/soft) (SA), Use of aesthetics (UA), Color used (CU), Searching (SB), Polite/Direct (PD), Chronemics/Time (CT) and Use of flash features (UF).

\section{2- Headings}

By employing Hall's dimensions, Wurtz [1] carried out a quantitative evaluation in order to discover and elucidate the variations within website samples of both high context and low context cultures. To support his analyses, various nations were first assessed as either High Context (HC) or Low Context (LC). Particularly, Japan, China, and Korea were classified under HC while United States, Sweden, Germany, Norway, Finland and Denmark were classified as LC. In Wurtz's study, navigation was based on the attributes of the websites. On the other hand, Wurtz used the analytical model proposed by Thorlacius [6] and dwelt on the characteristics of the site which include animation, images, photographs and layout. These websites characteristics are relevant to our study in the sense that they are amongst the list of design parameters (DP) to be analyzed. Gygi and Spyridakis [7] proposed a cultural model that depended on the present demographic data and values so as to assess a school's website in Uzbek. This is based on the assumption that "...web sites designed by local producers for local users would embody and exhibit identifiable cultural markers". Additionally, they assessed the impact of language (English or Russian) in the Uzbek secondary school website. In the light of Ref [7], our study analyzed websites built for local users, though the LEEGA websites are all in English and not in any local Nigerian language.

To dictate the cultural context profile of the website of the South Africa (SA), Yeratziotis and Greunen [8] used the cultural model developed by Hall, to determine if the site's design and implementation is in accordance with the United Kingdom guidelines of e-government. They presented an evaluation of the SA website on a three point 
scale compliancy level. It was however discovered in the study that the SA government site is not in accordance to the UK guidelines of website development. The website only furnishes a fundamental level of fulfilment for service delivery. Herselman and Greunen [9] carried out a global survey on cultural contexts variations which is aimed at supporting the government in making sure that their websites address the specific needs of the users. Their argument is on their contribution to the websites' usability and effectiveness. The study was done using questionnaire methods applied on selected populations. Ten participants were identified through purposive sampling and divided into two groups (5 persons) in low-context culture and (5 persons) in high context culture. Results of the study went contrary to literature and has it that high-context participants preferred more low-context styles when using government websites. Though this is a global survey, it informed our research method as well as the attributes of high and low context cultures presented in Table 1 and Table 2. The work also presented two continuums (Fig. 2) for high and low context cultures; wherein it is evident that Africa (or Nigeria) is still absent in discussions concerning website design and analysis.

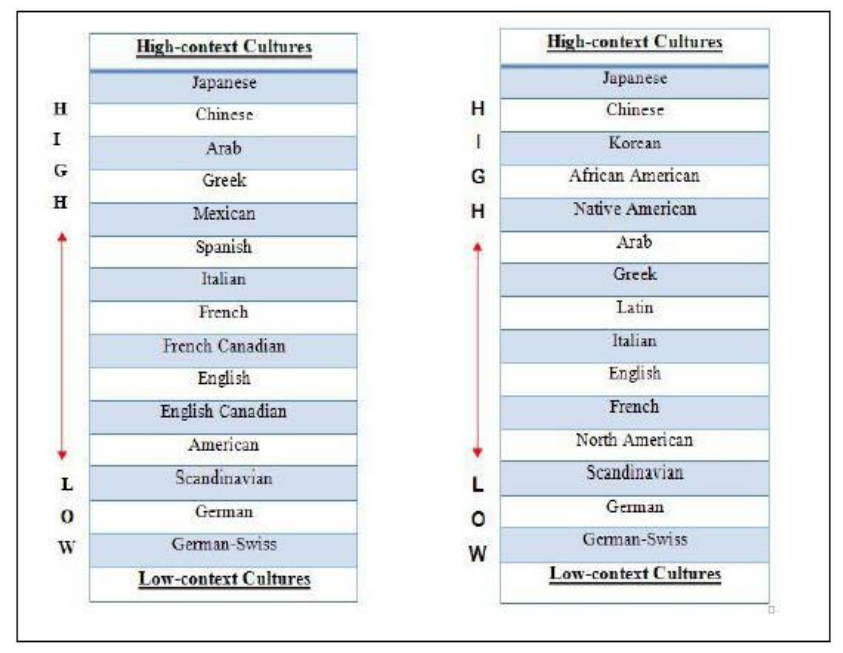

Fig. 2 High and Low-context Nationalities Scale according to Culture [9]

Vatrapu and Pérez-Quiñones [10] found out that the main hindrance to the development of interfaces is the insufficiency of empirical proofs showing the impact of culture on usability engineering approaches. Therefore, they presented a controlled experiment in order to study the impact of culture on usability testing. After two independent Indian groups tested a website for usability, the result generated shows that culture remarkably influences the success of structured interviews. The absence of a comprehensive review on the function of culture in web development spurred Moura, et al. [11] to compile and synthesize results of 90 prior studies. The review was structured into three major strongholds namely, the manifestation of cultural values in websites, the investigation of cultural markers in websites, and the influence of culture on users' perceptions of online stimuli. Finally, they suggested that the reviewed studies presents a convincing case of considering culture while adapting web features to meet expectations of the user. Refs $[10,11]$ shows the need for performing a study such as ours, wherein the impact of culture context heuristics on websites are evaluated. At other quarters, it was discovered that designers hardly undertake the time consuming and costly task of creating culturally tailored forms of websites. This issue was traced to the absence of standard best practices or guidelines of web design and development. Having previously identified the relationship that exist between design features, cultural and HCI factors, Alexander, et al. [12] aimed at developing a set of guidelines for designing cross-cultural websites. They proposed 5 steps of development, which include evaluation of the usage of design elements between cultures, identification of prominent design elements, organization of cultural factors, organization of $\mathrm{HCI}$ factors, and finally development the cross-cultural design guidelines.

Umeh, et al. [13] evaluated the cultural profiles of websites to some Nigerian institutions, they include Cooperate Affairs Commission of Nigeria, Federal Inland Revenue Service of Nigeria, National Agency for Food and Drug Administration Commission of Nigeria, National Pension Commission of Nigeria, Nigeria Export Promotion Commission, Nigerian Tourism Development Corporation, National Emergency Management Agency of Nigeria. This is the first that investigates the cultural dimensions of Nigerian websites. The analyses performed using online survey method showed that websites of these institutions are high context styles in terms of animation/images, value promotion, transparency level, navigation, use of links, color, search boxes and polite/direct approach. Oyefolahan, et al. [14] assessed the usability and accessibility of websites owned by Nigerian commercial banks using automated tools and the manual inspection method. This was aimed at determining their conformance with the Web Accessibility Initiative. Findings of the study showed that significant enhancements are still needed in most of the websites. Although, ref [14] analyzed Nigerian websites like we did in our study, its analyses was absent insights on cultural context analyses. However, from the study we learnt of the existence of automated tools for website analyses and by searching the internet, we discovered SEO SiteCheckup [15] and Smallseotools [16], which was also used by our respondents.

Hofstede's cultural dimensions for Canadian immigration website was analyzed using Chinese, Indian, and Nigerian and French-speaking international students 
[17]. The five dimensions include; Individualism/Collectivism, Power Distance, Uncertainty Avoidance, Time Orientation and Masculinity/Femininity. More so, analyses of other websites were for the following objectives; healthcare in European countries [18], cues for taking risks [19], e-commerce usability [20], and crosscultural translation for Australia, China, and Saudi Arabia [21]. On a different perspective i.e. technology adoption, ref [22] e-government learning services. As Vatrapu and Pérez-Quiñones [10] puts it, "Cultural background influences the design methods employed in building interfaces". Based on these premises, we aim to evaluate the culture context heuristics of websites of law enforcement e-government agencies (LEEGA) in Nigeria using several design parameters. Refs [8,9] analyzed the culture context heuristics using the parameters gleaned from Table 1 (observations of the characteristics of high and low cultures websites) and Table 2 (present the other perspectives for values and features that are necessary when designing software products).

Table 1: Observations for High/Low Contexts in Web Design [1]

\begin{tabular}{|c|c|c|}
\hline Parameter & HC Cultures & LC Cultures \\
\hline Animation & $\begin{array}{c}\text { High use of } \\
\text { animation, especially } \\
\text { in connection with } \\
\text { images of moving } \\
\text { people. }\end{array}$ & $\begin{array}{c}\text { Lower use of animation, } \\
\text { mainly reserved for } \\
\text { highlighting effects (e.g., } \\
\text { of text, active links, } \\
\text { logos) }\end{array}$ \\
\hline $\begin{array}{c}\text { Promotion of } \\
\text { Values }\end{array}$ & $\begin{array}{c}\text { Images promote } \\
\text { values characteristic } \\
\text { of collectivist } \\
\text { societies (e.g., being } \\
\text { in good } \\
\text { physical shape, } \\
\text { spending time with } \\
\text { family and friends) }\end{array}$ & $\begin{array}{l}\text { Images promote values } \\
\text { characteristic of } \\
\text { individualistic societies } \\
\text { (e.g. individuals are } \\
\text { portrayed being in a more } \\
\text { relaxed situations, such } \\
\text { as holiday or listening to } \\
\text { music - value personal } \\
\text { time) }\end{array}$ \\
\hline $\begin{array}{l}\text { Individuals } \\
\text { separate } \\
\text { or together } \\
\text { with the } \\
\text { product } \\
\end{array}$ & $\begin{array}{l}\text { Featured images } \\
\text { depict products and } \\
\text { merchandise in use } \\
\text { by individuals }\end{array}$ & $\begin{array}{c}\text { Images portray lifestyles } \\
\text { of individuals, with or } \\
\text { without a direct emphasis } \\
\text { on the use of products or } \\
\text { merchandise }\end{array}$ \\
\hline $\begin{array}{c}\text { Level of } \\
\text { transparency }\end{array}$ & $\begin{array}{l}\text { Links promote an } \\
\text { exploratory } \\
\text { approach to } \\
\text { navigation on the } \\
\text { website; process- } \\
\text { oriented }\end{array}$ & $\begin{array}{l}\text { Clear and redundant cues } \\
\text { in connection with } \\
\text { navigation on a website; } \\
\text { goal-oriented }\end{array}$ \\
\hline $\begin{array}{c}\text { Linear vs. } \\
\text { parallel } \\
\text { navigation on } \\
\text { the } \\
\text { Web site }\end{array}$ & $\begin{array}{c}\text { More of a } \\
\text { montage/layer-upon } \\
\text { layer approach. Many } \\
\text { sidebars and menus, } \\
\text { opening of new } \\
\text { browser windows for } \\
\text { each new page }\end{array}$ & $\begin{array}{c}\text { Few sidebars and menus, } \\
\text { constant opening in same } \\
\text { browser window }\end{array}$ \\
\hline
\end{tabular}

Table 2. High- and Low-context features [9]

\begin{tabular}{|c|c|}
\hline High-context features & Low context features \\
\hline Polychronic aspects of time & $\begin{array}{c}\text { Monochronic aspects of } \\
\text { time }\end{array}$ \\
\hline $\begin{array}{c}\text { Multiple use of images and/or } \\
\text { banners }\end{array}$ & $\begin{array}{c}\text { Less use of images } \\
\text { and/or } \\
\text { banners }\end{array}$ \\
\hline $\begin{array}{c}\text { Multiple use of links (external links } \\
\text { promote a collectivist nature, working } \\
\text { together) }\end{array}$ & Less use of links \\
\hline Use of Flash features & $\begin{array}{c}\text { Little use of Flash } \\
\text { features }\end{array}$ \\
\hline $\begin{array}{c}\text { Being polite and indirect } \\
\text { with the customer (soft-sell approach) }\end{array}$ & $\begin{array}{c}\text { Being direct and even } \\
\text { confrontational }\end{array}$ \\
\hline $\begin{array}{c}\text { Use of aesthetics to elicit } \\
\text { emotion (harmony, beauty, } \\
\text { nature, art, designs) }\end{array}$ & $\begin{array}{c}\text { Direct communication } \\
\text { (focus on rank and } \\
\text { prestige, superlatives, } \\
\text { terms and conditions) }\end{array}$ \\
\hline
\end{tabular}

\section{3- Headings}

The research method for the study involves the following; identification of participants, (online) dissemination of the online survey to participants, analysis of survey data (questionnaires), preparation of survey report and presentation of results. Note that analyses here implies a two-fold evaluation which involves first, the analysis performed by the survey participants and second, the analysis we performed after we collated responses of the participants. Pertinent literature such as cultural anthropology, e-government, web design and computermediated communication were reviewed. As a result, we came up with a questionnaire that will allow the easy and accurate assessment of the law enforcement agencies' websites through the online survey method. A sample size of experts in web development and information technology were drawn from the six geopolitical regions of Nigeria contributed to the survey findings. Six groups (3 persons from each geo-political zone), making it a total of 18 persons. The questionnaire was designed to have biographical information, the design parameters (shown in Table 1 and Table 2, with some instructions of Table 3) and a section for open ended answers. Note that 13 design

parameters was used for the analyses. Aside using manual inspection method as well as some automated tools $[15,16]$ to reach conclusions while analyzing the LEEGA websites, we simply instructed the respondents to choose from the following 3 points namely High, Low and Not Applicable (NA). On the need for providing some guidance for the respondents, we established in Table 3 some rules to further guide the respondents. Since the tables culled from [1,9] were not explicit on how many 
images/banner constitute high/low, how many colors constitute high/low, how many links constitute high/low and what time actually means on the sites etc. For chronemics (time), we instructed the respondents to judge context heuristics using these factors which include emphasis on relationship building, wide array of content, more exploration time, greater depth and breadth of content and busier design. On the promotion of values we instructed the respondents to look out for images that depict values such as unity, team work, cooperation, togetherness, and a cordial relationship with the masses. For aesthetics, they were instructed to use beauty (nature, art or design), emotion and sensation as opposed to pure intellectuality. Other specific parameters for judging site features are listed in Table 3.

Table 3. Rules for Further Guidance

\begin{tabular}{|c|c|c|}
\hline Parameters & High & Low \\
\hline AIB & $4 \&$ above & $3 \&$ below \\
\hline $\mathrm{CU}$ & $4 \&$ above & $3 \&$ below \\
\hline ML & Above 100 & 100 and below \\
\hline UA & $\begin{array}{c}2 \text { out of the } 3 \\
\text { parameters }\end{array}$ & $\begin{array}{c}\text { Less than } 2 \text { of the } \\
\text { parameters }\end{array}$ \\
\hline SB & 1 or more search boxes & No search box \\
\hline CT & $\begin{array}{c}3 \& \text { above factors for } \\
\text { time }\end{array}$ & $\begin{array}{c}2 \text { or less factors for } \\
\text { time }\end{array}$ \\
\hline
\end{tabular}

Additionally, to automatically check whether a site has flash technology we instructed the respondents to use SEO SiteCheckup [15] or do a manual check by right clicking anywhere on the website and by checking for the presence of "Zoom in" and "About Adobe Flash Player" at the top and bottom of the box that appears. Additionally, we also instructed them to check the number of links on the sites using Smallseotools [16].

\section{4- Results and Discussion}

Recall that we simply instructed the respondents to choose from the following 3 points namely High, Low and Not Applicable. This simple three point method is suitable for evaluating the above-listed heuristics of e-governance websites. The collection of the responses took 8 days and afterwards we analyzed them to form the results of this study. Since the questionnaire involved a section for open ended answers, we also collated and analyzed the responses. Specifically, we assembled the results of all the experts and we used the choice of the majority to decide whether a design parameter (DP) is either high or low context. The results collation and analyses are listed below (in Table 4 and Table 5). Under each LEEGA webpage, we presented and discussed the reasons why respondents described a particular heuristic as either high or low context (as guided in Table 3, Table 4 and Table 5). Beside each discussion, we italicized and placed in parenthesis the matching culture context.

Table 4. Context Results for Agencies I

\begin{tabular}{|c|c|c|c|c|c|c|c|}
\hline DP & NAF & NN & NA & NPF & NPS & NIS & NSCD \\
\hline AIB & High & Low & High & Low & High & High & High \\
\hline PV & High & High & Low & High & High & Low & High \\
\hline IS & N/A & N/A & N/A & Low & High & Low & Low \\
\hline LT & High & High & High & High & High & High & High \\
\hline NLP & Low & Low & High & Low & Low & Low & Low \\
\hline ML & High & High & High & Low & Low & High & High \\
\hline SA & Low & Low & Low & Low & High & Low & Low \\
\hline UA & High & Low & High & Low & High & Low & High \\
\hline CU & High & Low & High & High & Low & Low & High \\
\hline SB & High & High & High & Low & Low & Low & High \\
\hline PD & High & Low & Low & Low & High & High & Low \\
\hline CT & High & Low & High & High & High & Low & High \\
\hline UF & Low & Low & Low & Low & Low & Low & Low \\
\hline
\end{tabular}

Table 5. Context Results for Agencies II

\begin{tabular}{|c|c|c|c|c|c|c|c|}
\hline DP & NCS & FRSC & FFS & DIA & NDLE & ICPC & EFCC \\
\hline AIB & High & High & High & High & High & Low & Low \\
\hline PV & High & High & High & High & High & Low & High \\
\hline IS & Low & High & N/A & Low & High & Low & N/A \\
\hline LT & High & High & Low & High & High & High & High \\
\hline NLP & Low & High & Low & Low & High & Low & High \\
\hline ML & Low & High & Low & Low & Low & High & Low \\
\hline SA & Low & High & Low & Low & High & Low & Low \\
\hline UA & Low & High & High & Low & Low & Low & Low \\
\hline CU & High & Low & High & High & High & Low & Low \\
\hline SB & High & High & Low & High & High & Low & High \\
\hline PD & Low & High & Low & Low & Low & Low & Low \\
\hline CT & Low & High & High & Low & High & Low & Low \\
\hline UF & Low & Low & Low & Low & Low & Low & Low \\
\hline
\end{tabular}




\section{4-1- Nigerian Air Force (NAF)}

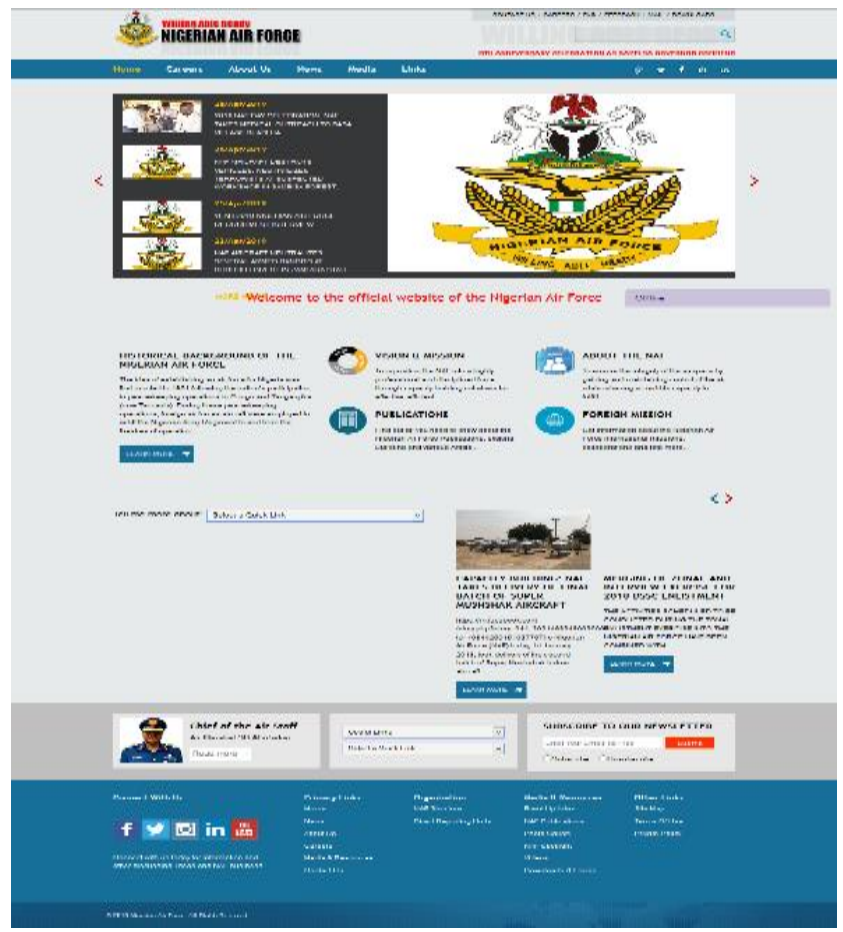

Fig. 3 Welcome Page of the Nigerian Air force [23]

The colors on the NAF website (Fig. 3) are light red, blue, white, yellow and black (high) while the alternating images/banners are 10 in number (high). On PV, some of the values promoted with photographs include togetherness, cooperate responsibility to the society and unity (high). More so, the picture where the force personnel were sharing food depicts unity and cooperative responsibility. Most of the respondents chose N/A for IS on the website and there reasons was that it promotes service delivery and not product sales. On level of transparency, they maintained the site is exploratory (high), while, for navigation they chose (low) because the site has few side bars and open in the same browser. On the use of aesthetics, most respondents said the site is beautiful and has pure emotion (high) as well as a friendly sell approach (low). The site has one search box (high) while for chronemics, the site displays some attempt at relationship building (high). The site has no flash features (low) and the links on the site are 115 in number with 110 internal and 5 external links (high).

\section{4-2- Nigerian Navy (NN)}

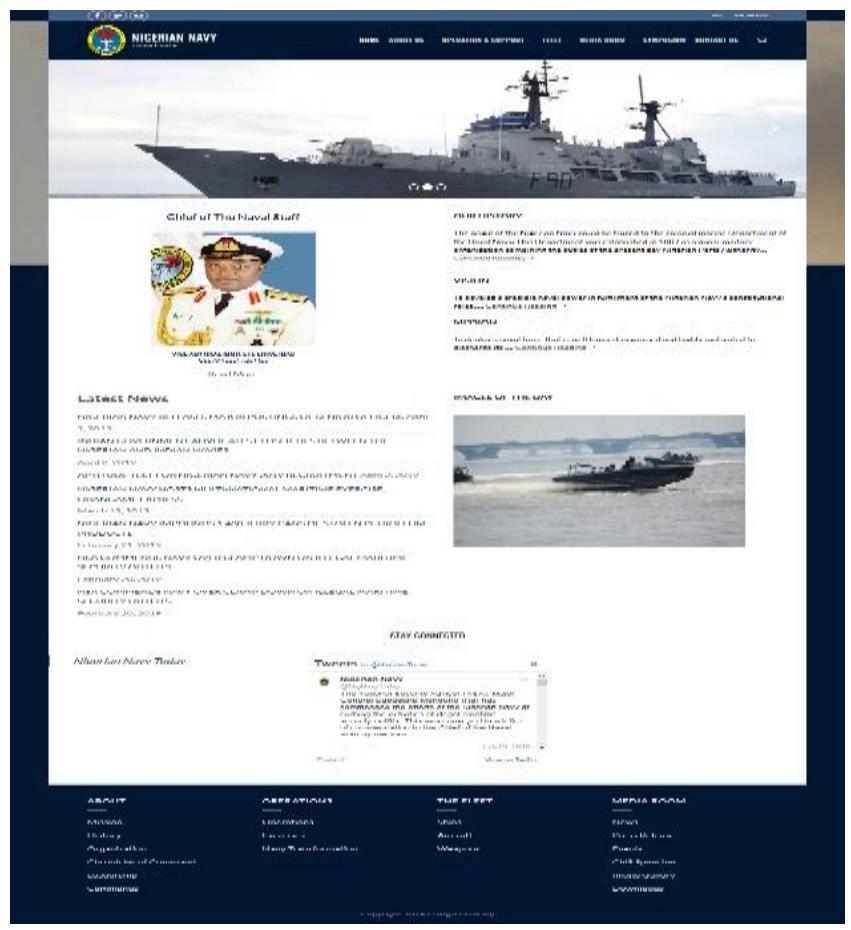

Fig. 4 Welcome Page of the Nigerian Navy [24]

Here (Fig. 4), the colors used for the website design are yellow, blue and white (low) while the alternating images/banners are 3 in number (low). On promotion values, the picture of personnel standing together depicts unity (high). The approach of sell here is that of (low) context, this is because the images present on the site makes no effort to relate with the public (N/A). The images does not suggest politeness but rather suggests a direct and confrontational position, this is largely because of the picture of the warship and that of the soldiers stationed to shoot (low). On navigation they chose (low) because the site has few side bars and open in the same browser. On level of transparency, they maintained the site is exploratory (high), while for navigation they chose (low) because the site has few side bars and open in the same browser. On the use of aesthetics, most respondents agreed that the site is simple yet beautiful but does not involve art, nature and designs (low). The site has no flash features (low) and the links on the site are 115(high) in number with 103 internal and 12 external links. 


\section{4-3- Nigerian Army (NA)}
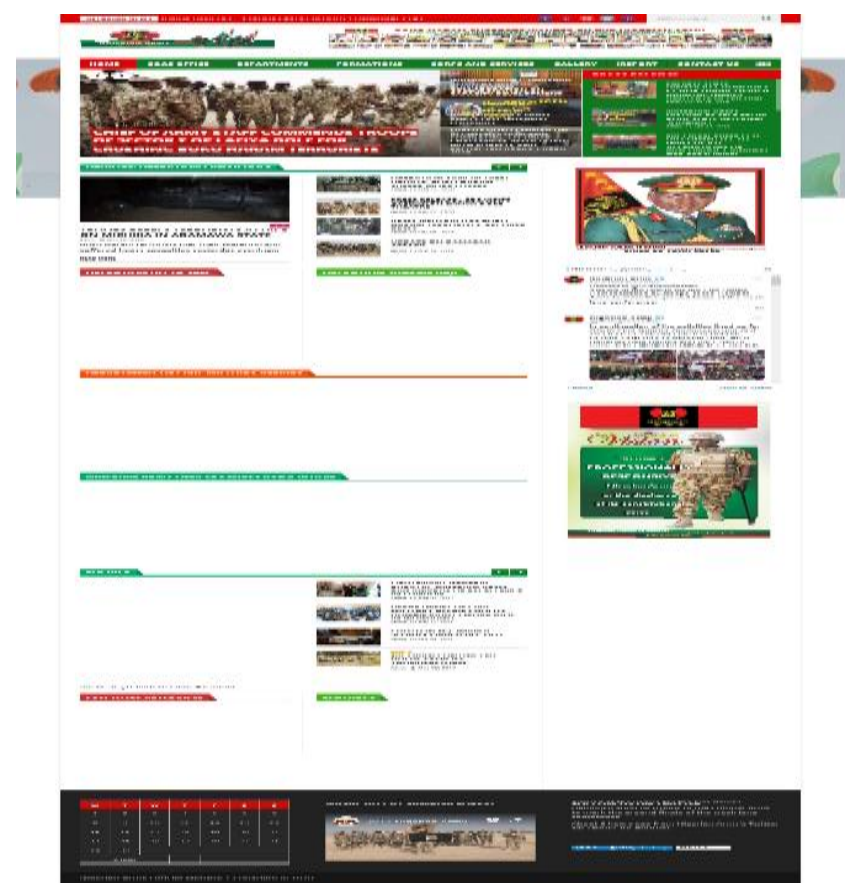

Fig. 5 Welcome Page of the Nigerian Army [25]

On the NA website (Fig. 5), two alternating banners and other images were scattered all over the home page (high). The colors used for the website design include green, red, white and black (high). On PV, most of the respondents agreed that the website did not promote values such as cordial relationship with the populace (low). The site maintains a direct sell approach (low); owing to images of guns, bullets and no relationship with the society. This is traceable to their aim of protecting the nation from external threats through the use of force. For IS, they chose $N / A$, because the heuristic is not applicable for the website. For NLP, the respondents agreed that the NA site is linear due to the many side bars and menus (high). At least a search box can be found on the site (low). On level of transparency, they maintained the site is exploratory (high). On the use of aesthetics, most respondents agreed that the site is beautiful and shows some form of nature and design (high). For chronemics, they agreed on more exploration time, greater depth and breadth of content and busier design (high). The site has no flash features (low) and the links on the site are 238 (high), 210 internal and 28 external links.

\section{4-4- Nigerian Police Force (NPF)}

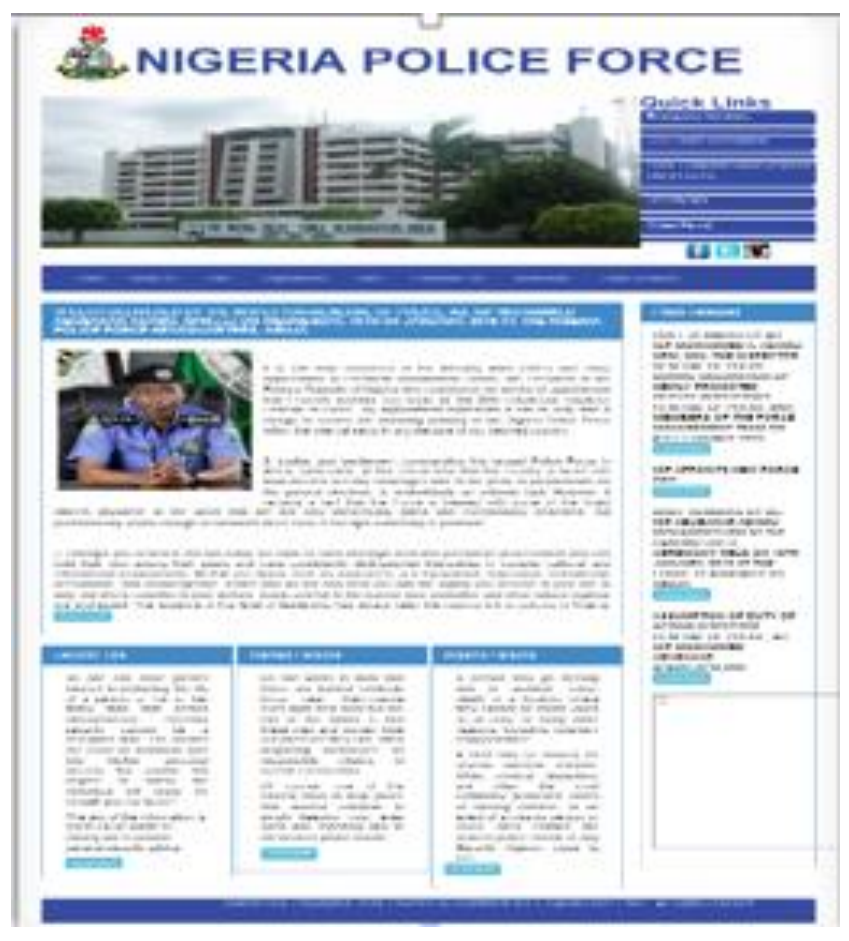

Fig. 6 Welcome Page of the Nigerian Police Force [26]

The NPF home page (Fig. 6) has 3 alternating images (low) and the colors used for the website design include white, light, navy blue and dark blue (high). On the promotion of values, most of the respondents agreed that the NPF website promote values such as togetherness (high); this is expressly shown with 2 images of police personnel on a parade. On the level of transparency, the site used an exploratory and process-oriented approach (high). On the navigation type, the site has few side bars, many menus and it opens in same browser window (low). The sell approach is of low context i.e. the site employed a direct method. On the use of aesthetics (low), most respondents agreed that the site is just simple and cannot be described as beautiful. Additionally, it does not involve art, nature, designs or any form of emotion. For chronemics, they agreed on more exploration time, greater depth and breadth of content but did not agree on busier design (high). The site has no search box (low), no flash features (low) and the links on the site are 77 (low) with 73 internal and 4 external links. 


\section{4-5- Nigerian Prisons Service (NPS)}
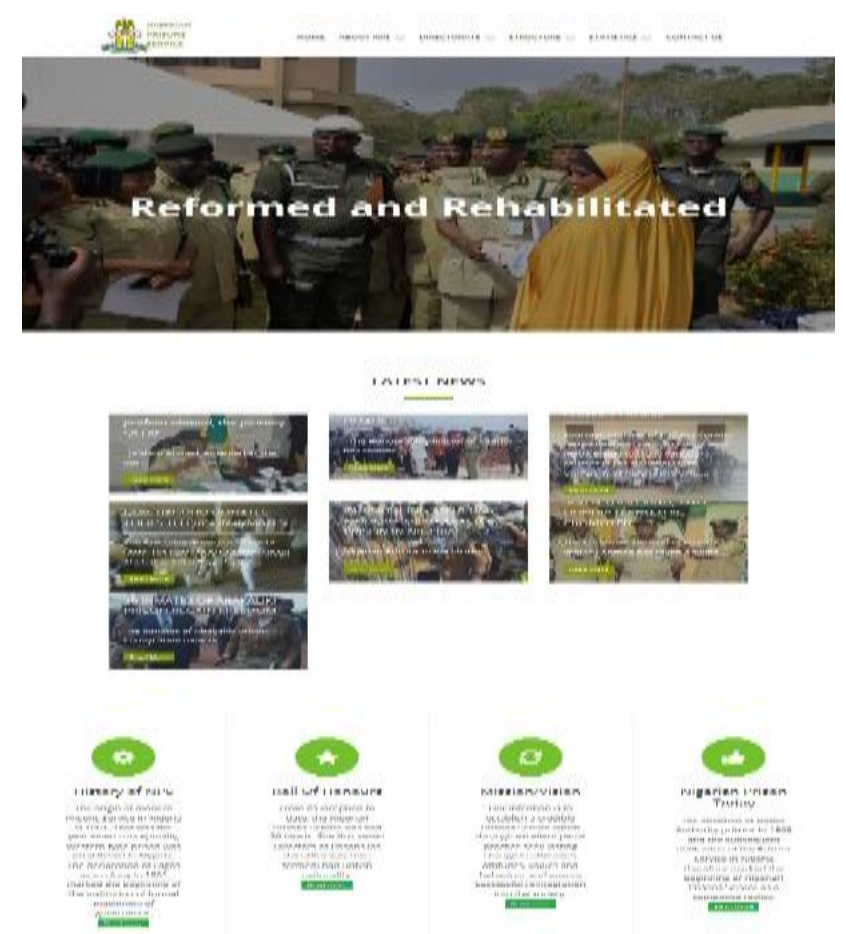

Fig. 7 Welcome Page of the Nigerian Prisons Service [27]

The NPS home page (Fig. 7) has 9 alternating images/banner (high) and the colors used for the website design include white, green and black (low). On the promotion of values, most of the respondents agreed that the NPS website promote values such as industry (on the part of the inmates), unity and perseverance (high). These values are clearly shown through the images of the inmates and the officers as well as the pictures of graduating inmate-students. These pictures also depicts IS i.e. the individuals together with the product (high). In this case the product(s) are the inmates that are in need for reformation. On the navigation type, the site has few side bars and menus (low). On the level of transparency, the site used an exploratory and process-oriented approach (high). The sell approach is of (high) context because the site has a desire to build relationships as well as a wide array of content. On the use of aesthetics, most respondents agreed that the site cannot be described as beautiful though it shows emotion and sensation as against pure intellectuality (high). The site depicts a polite approach (high) and displays some attempt at relationship building (high) for chronemics. The site has no search box (low), no flash features (low) and the links on the site are 50 (low), with 43 internal and 7 external links.

\section{4-6- Nigerian Immigration Service (NIS)}
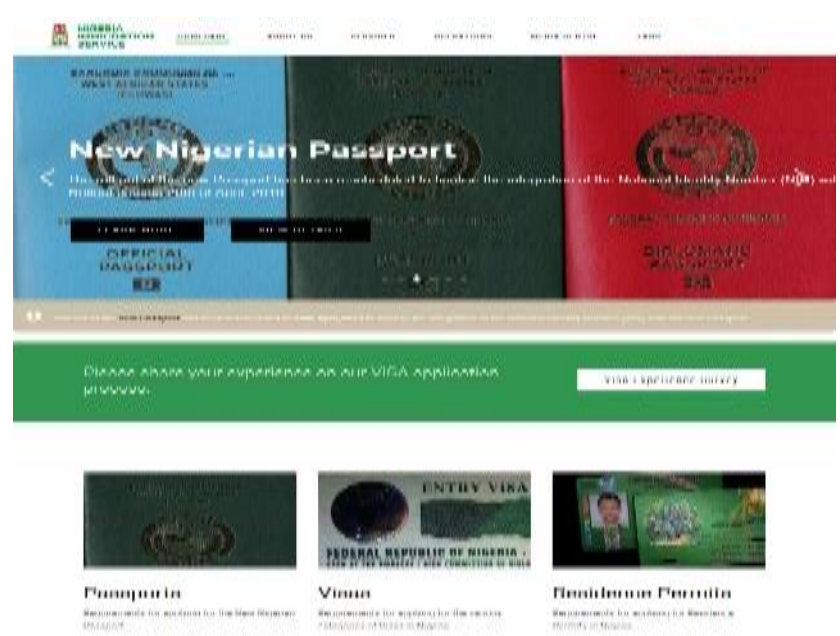

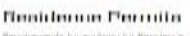
(1)

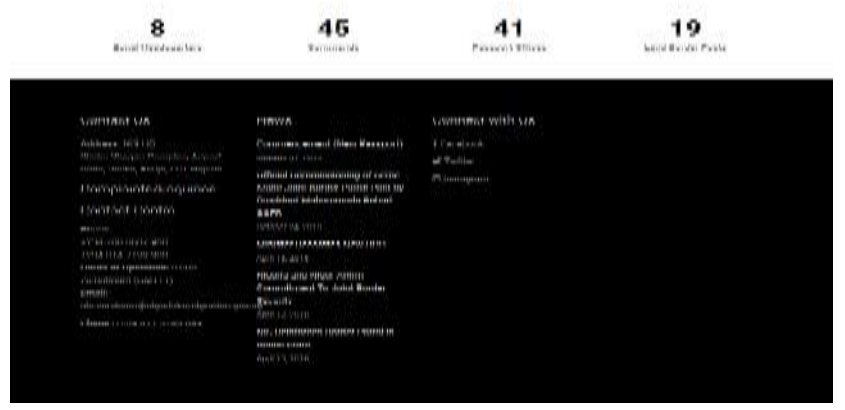

Fig. 8 Welcome Page of the Nigerian Immigration Service [28]

The NIS home page (Fig. 8) has 5 alternating images/banner (high) and the colors used for the website design include white, green and black (low). On promotion of values, most of the respondents agreed that the NIS website does not promote any value through the use of pictures (low). On IS, the site has no images together with any product (low). On the level of transparency, the site used an exploratory and process-oriented approach (high). On the navigation type, the site has few side bars and menus and opening in the same browser (low). The sell approach is of (low) context because the site employed a direct method. On the use of aesthetics, most respondents agreed that the site is not beautiful, does not display any form of emotion or sensation (low). The site depicts a polite approach (high) and but does not displays any attempt at relationship building ( $h i g h$ ) for chronemics. The site has no search box (low), no flash features (low) and the links on the site are 103 (high) with 97 internal and 6 external links. 


\section{4-7- Nigeria Security Civil Defense Corps (NSCDC)}

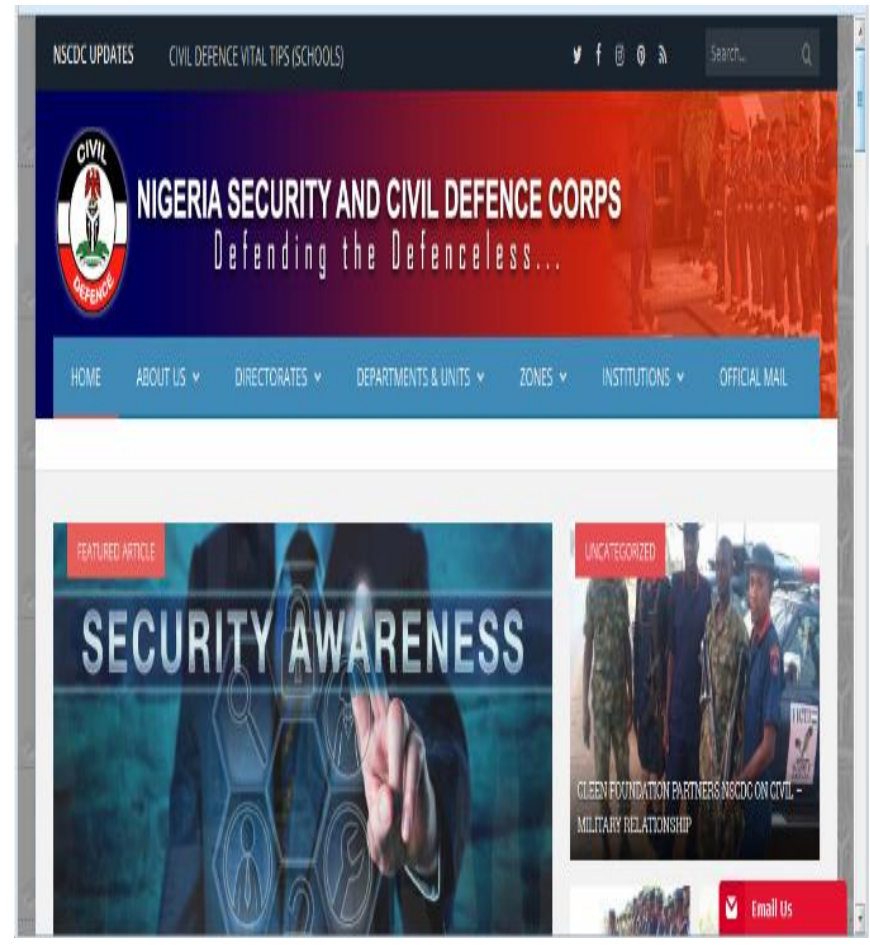

Fig. 9 Welcome Page of the Nigeria Security Civil Defense Corps [29]

The NSCDC home page (Fig. 9) has 5 alternating images/banner (high) and the colors used for the website design include red, blue, white, black, green, and purple (high). On PV, most of the respondents agreed that the NSCDC website promote most especially the defense for the helpless (high). Another value promoted here is cooperation (with other agencies); a picture where the NSCDC personnel are standing together with Army officers. On IS, their commandant general can be seen sitting alone with an indifferent look (low). On the level of transparency, the site used an exploratory and processoriented approach (high). On the navigation type, the site has few side bars and opening in the same browser (low). The sell approach is of (low) context because it does not depict any form of friendliness with the masses. The site is also confrontational and strongly maintains an impersonal atmosphere (low). On the use of aesthetics, the respondents agreed that the mixture of red and blue (or how blue gives way to red) makes the site very beautiful (high). This site according to the respondents suggests some form of emotion and sensation. For chronemics, it is clearly evident that the site has a wide array of content, more exploration time, greater depth and breadth of content and busier design (high). The site has a search box (high), no flash features (low) and the links on the site are 170 (high) with 164 internal and 6 external links.

\section{4-8- Nigeria Customs Service (NCS)}

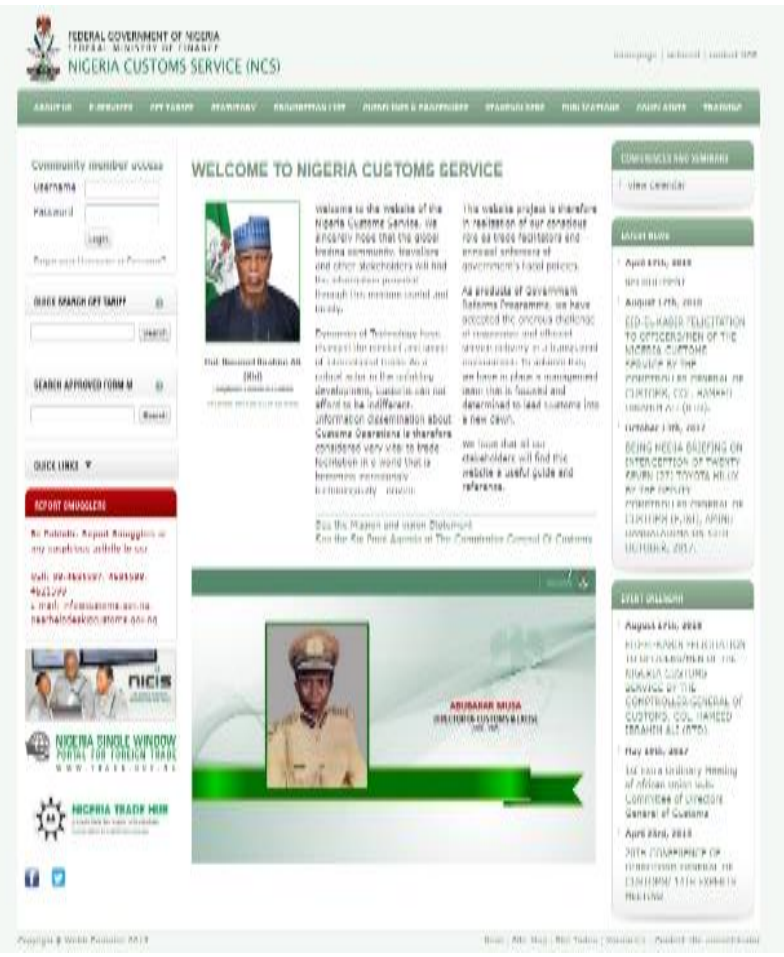

Fig. 10 Welcome Page of the Nigerian Customs Service [30]

The NCS home page (Fig. 10) has 3 images and the alternating images of their past controllers (high). The colors used for the website design include green, ash, red, white and black (high). The image on the lower left hand side of the site promotes values such as cooperation and team work (high). On IS, the site has no images together with any product (low). On the navigation type, the site has few side bars and menus and opening in the same browser (low). On the level of transparency, they agreed that the site is exploratory and process-oriented (high). The sell approach is of (low) context because the site reveals no form of friendship with anyone. On the use of aesthetics, the respondents agreed that there is nothing visually appealing about the site (low). It is bland and without nature, art, design or any form of emotion/ sensation. The site has two search boxes (high) on the homepage for CET Tariff/Approved Form M. The CET page on the website has two search boxes too; for HS codes and for keywords. The NCS site is the only site with more than two search boxes. The atmosphere of the site is direct and confrontational (low). For chronemics, it is obvious that the site does not have a wide array of content, nor does it requires more exploration time, for site of content. In fact, the design is less busy (low). Additionally, the site has no flash features (low) and the links on the site are 95 (low) with 77 internal and 18 external links. 


\section{4-9- Federal Road Safety Corps (FRSC)}

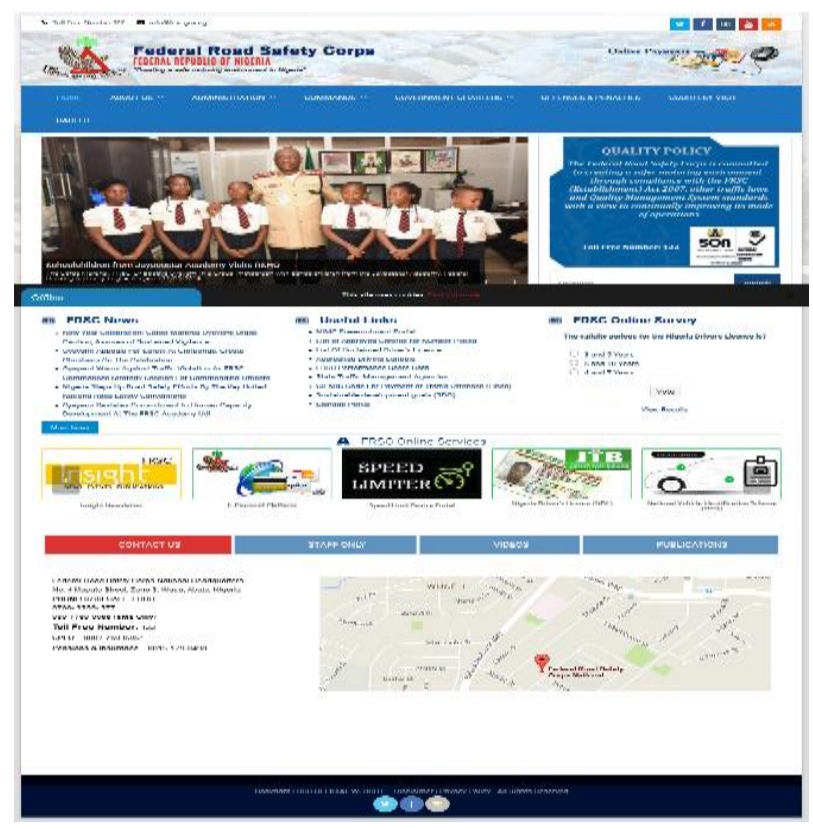

Fig. 11 Welcome Page of the Nigerian Federal Road Safety Corps [31]

The FRSC home page (Fig. 11) has 11 images (high) and the colors used for the website design include blue, red and white (low). The site promotes values such as cooperation, industry and team work through pictures of group leaning (high). For IS, the picture where the officers are with the children also shows corporate responsibility (high). On the level of transparency, the participants agreed that the site is exploratory and process-oriented (high). On the navigation type, the site has many side bars and opens in the same browser (high). The sell approach is of high context because of the friendliness between the officers and the children (high). This site was described as beautiful even though it is somewhat simple (high). Additionally, the site displays some form of emotion and involves a polite approach (high). For chronemics, it is clearly evident that the site encourages relationship building, has a wide array of content and requires more exploration time (high). The site has at least a search box (high), no flash features (low) and the links on the site are 186 (high) with 143 internal and 43 external links.

\section{4-10- Federal Fire Service (FFS)}

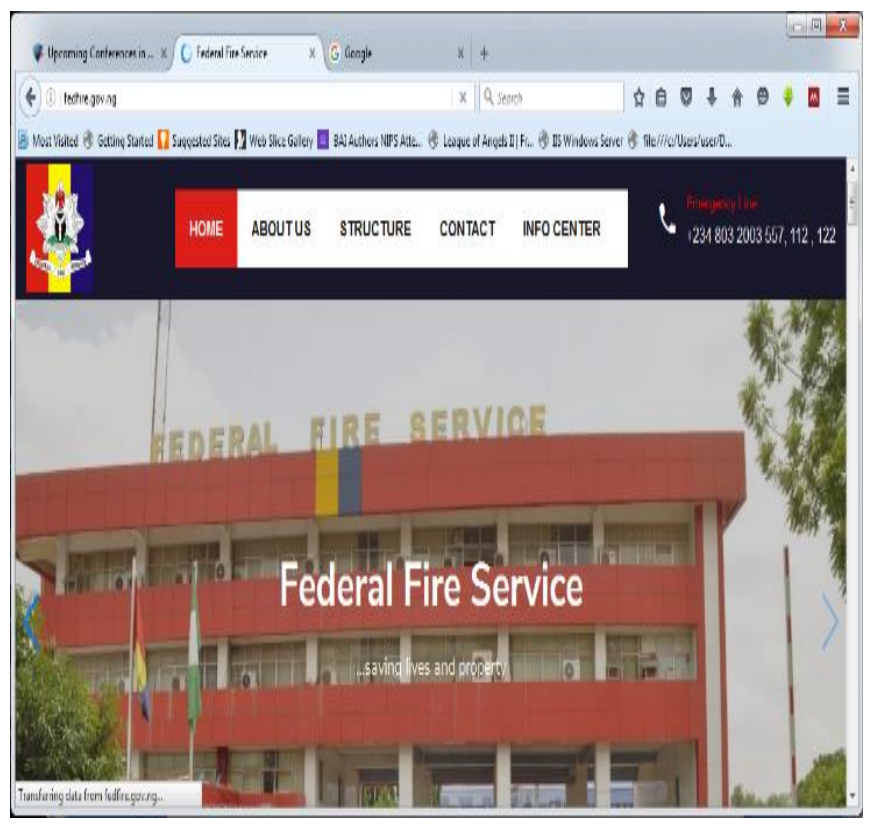

Fig. 12 Welcome Page of the Federal Fire Service [32]

The FFS home page (Fig. 12) has 5 alternating images/banner (high) and several other images placed on the gallery section. The colors used for the website design include white, red, green and black (high). On PV, the respondents agreed that the FFS website promotes safety (i.e. saving lives and property) as well as cooperation and teamwork using the pictures where their personnel are on parade (high). On IS, the site has no images of individuals together with any product (low). On the level of transparency, the participants agreed that the site involves clear and redundant cues in connection with navigation (low). On the navigation type, the site has few side bars/menus and opens in the same browser (low). The sell approach is of (low) context because the site employed a direct method. On the use of aesthetics, most respondents agreed that the site is beautiful but it doesn't display any emotion (high). The exudes a direct approach (low) and for chronemics, it is clearly evident that the site has a wide array of content, more exploration time, greater depth and breadth of content and busier design (high). The site has no search box (low), flash features (low) and the links on the site are 73 (low) with 61 internal and 12 external links. 


\section{4-11- Defense Intelligence Agency (DIA)}

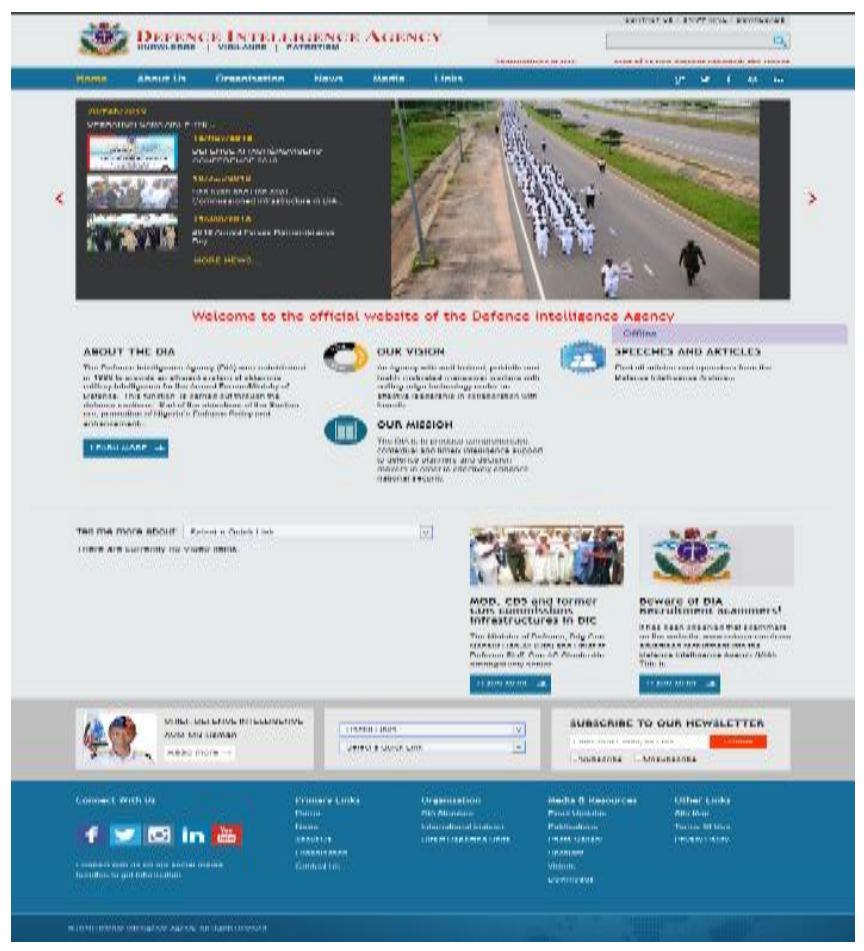

Fig. 13 Welcome Page of the Defense Intelligence Agency [33]

The DIA home page (Fig. 13) has 8 alternating images/banner (high) and the colors used for the website design include red, blue, white and yellow (high). On PV, the respondents agreed that the FFS website promotes fitness and being in good shape. The picture of officers matching on the road also depicts team work, cooperation, unity and professionalism (high). On IS, the site has no images together with any product (low). On the level of transparency, the site used an exploratory and processoriented approach (high). On the navigation type, the site has few side bars and menus and opens in the same browser (low). The respondents confirms that the site is direct and confrontational due to the picture of the war helicopter (low). The site has three search boxes (high); one search box can be found at the top of the home page, while two search boxes are found below that same page. For chronemics, it displays a far less attempt at relationship building and does not have a wide array of content (low). On the use of aesthetics, most respondents agreed that the site is beautiful but it doesn't display any form of emotion, nature, art or design (low). The site has no flash features (low) and the links on the site are 95 (low) with 94 internal and 1 external link.

\section{4-12- National Drug Law Enforcement Agency (NDLEA)}

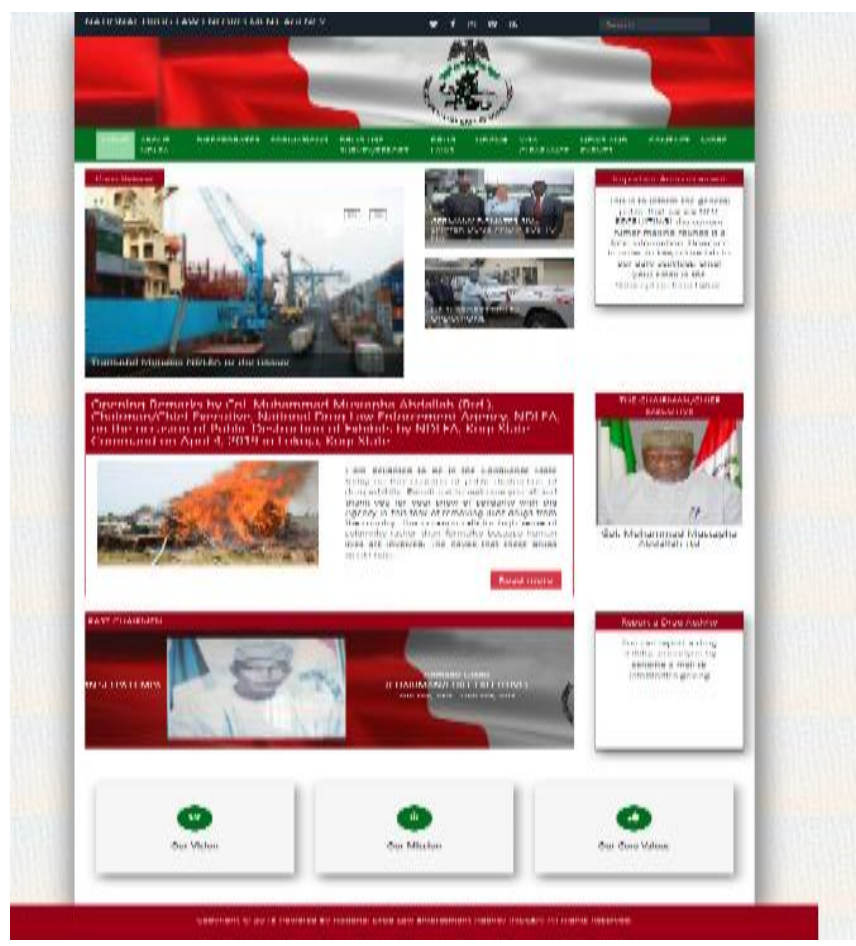

Fig. 14 Welcome Page of National Drug Law Enforcement Agency [34]

The NDLEA home page (Fig. 14) has 5 alternating images/banner and other images scattered on the site (high). The colors used for the website design include white, green, red (pure and dark) (high). On PV, the respondents agreed that the FFS website promotes deterrence and zero tolerance for drug crimes (high). The picture of officers from different agencies also shows team work and cooperation. The burning drugs also shows high context for IS. On the level of transparency, the site is exploratory and process-oriented (high). On the navigation type, the site has few side bars and opens in the same browser (high). On the sell approach, the collaboration with other agencies shows friendliness that suggests high context. The site has one search box (high) while for chronemics, the site displays some attempt at relationship building though it has no external links (high). On the use of aesthetics, the experts agreed that the site is neither beautiful nor does it display any form of emotion (low). The site exudes a direct atmosphere; this is expressly shown in the picture of the burning drugs - a zero tolerance for drug peddling. The site has no flash features (low) and the links on the site are 45 (low) with 45 internal and 0 external links. Additionally, the site the lowest number of external links in this study. 


\section{4-13- Independent Corrupt Practices and Other Related Offences Commission (ICPC)}

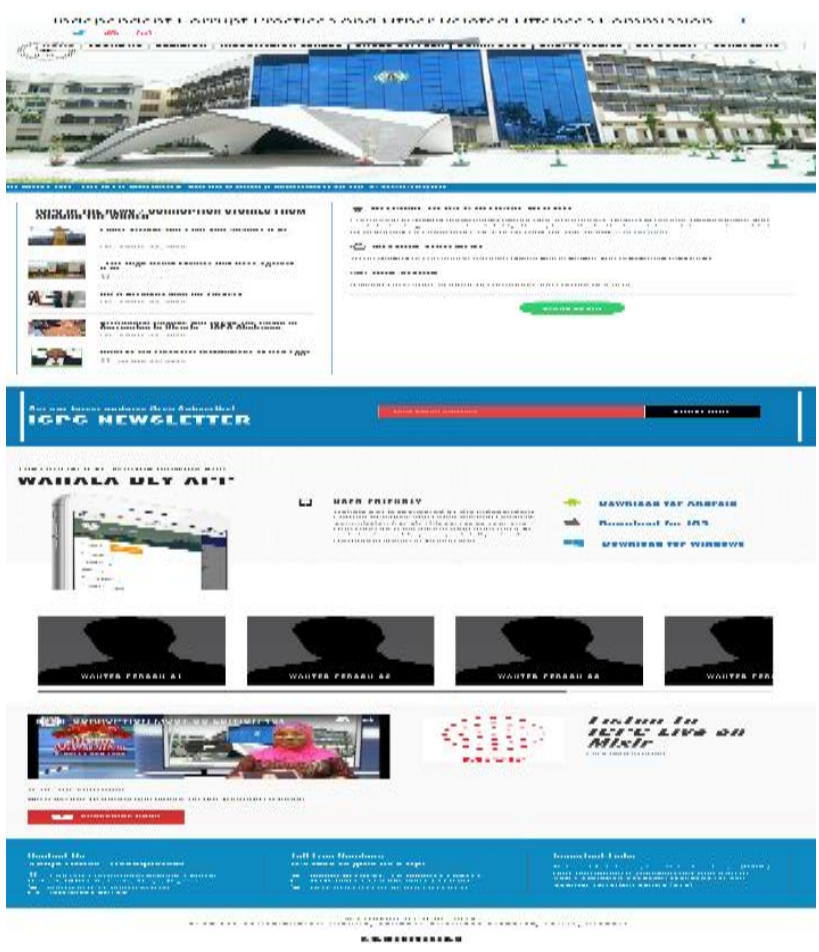

Fig. 15 Welcome Page of the Corrupt Practices and Other Related Offences Commission [35]

The ICPC home page (Fig. 15) has 3 alternating images/banner (low) and the colors used for the website design include white, blue and black (low). For PV and IS, no picture on the site promotes any form of values (low). On the level of transparency, the site is exploratory and process-oriented (high). On the navigation type, the site has few side bars and opening in the same browser (low). On the sell approach, the site suggest a hard sell orientation due to its cold and indifferent stance (low). The site has no search boxes (low) while for chronemics, the site makes no attempt at relationship building nor would it be adjudged to involve busier designs, therefore it depicts low culture context (low). On the other hand it has a wide array of content and requires more exploration time. On the use of aesthetics, the experts agreed that the site is beautiful but it does not have any special visual or animation effect (low). The site exudes a direct atmosphere (low). In addition, the site has no flash features (low) and the links on the site are 159 (high) with 148 internal and 11 external links.

\section{4-14- Economic and Financial Crimes Commission (EFCC)}

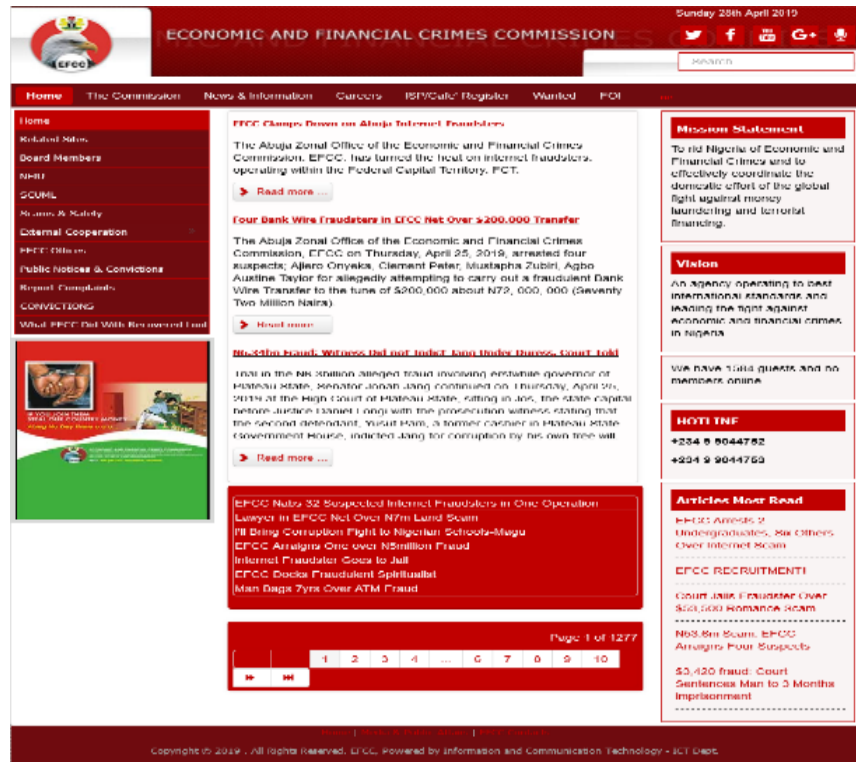

Fig. 16 Welcome Page of the Economic and Financial Crimes Commission [36]

The EFCC home page (Fig. 16) has 3 alternating images (low) and the colors used for the website include white, coffee brown and red (low). On PV, the picture of a handcuffed guy promotes deterrence (high). On the level of transparency, the site is exploratory and processoriented (high). On the navigation type, the site has many side bars and opens in the same browser (high). On SA, the site suggest a hard sell orientation (low); this is because the organization doesn't exist to favor anyone. The site has one search box (high) while for chronemics, the site makes no attempt at relationship building nor would it be said to include busier designs, though it has greater depth. For aesthetics, the experts agreed that the site is beautiful but it does not have any special visual /animation effect, nature or art (low). Also, the site doesn't show any form of emotion/sensation. The site has no flash features (low) and the links on the site are 69 (low) with 63 internal and 6 external links.

From the responses collated, we confirmed that the reviewed sites were mostly arranged in the same manner when it comes to the level of transparency. Here, the main menu of the sites are linearly placed (close to the top) and by clicking on them, it displays horizontal submenus. Additionally, several information are placed horizontally as side bars making most of the sites seem exploratory and process-oriented. Most of the respondents agreed that the sites do not possess flash technology. Note that flash is an outdated technology that is used to deliver rich multimedia content. This technology poses some difficulty for web crawlers that may intend to interpret. More so it has some hitch-prone issues when assessed using mobile devices. 
Table 6 presents the grand summary of collated results for the agencies i.e. it shows the cumulative choices made by respondents when assessing LEEGA websites. From this table it is clearly evident that these websites are of low context, however, one should note that the margin is not so wide. The second grand summary (Table 7) for the study presents the design parameters and the agency that are either high or low context.

Table 6. Grand Summary of Cultural-Context Result

\begin{tabular}{|c|c|c|c|c|}
\hline S/N & Agency & High & Low & N/A \\
\hline 1 & NAF & 9 & 3 & 1 \\
\hline 2 & NN & 4 & 8 & 1 \\
\hline 3 & NA & 8 & 4 & 1 \\
\hline 4 & NPF & 4 & 9 & - \\
\hline 5 & NPS & 8 & 5 & - \\
\hline 6 & NIS & 4 & 9 & - \\
\hline 7 & NSCDC & 8 & 5 & - \\
\hline 8 & NCS & 5 & 8 & - \\
\hline 9 & FRSC & 11 & 2 & - \\
\hline 10 & FFS & 5 & 7 & 1 \\
\hline 11 & DIA & 5 & 8 & - \\
\hline 12 & NDLEA & 9 & 4 & - \\
\hline 13 & ICPC & 2 & 11 & - \\
\hline 14 & EFCC & 4 & 8 & 1 \\
\hline & TOTAL & 86 & 91 & 5 \\
\hline
\end{tabular}

Consequent upon these tables, one can conclude that web designers for LEEGA follow the high context styles for animation, promotion of values, level of transparency, color used, searching and chronemics/time. On the other hand, the designers follow the low context style in terms of individuals separate or together with the product, navigation, sell approach, use of aesthetics, polite/direct and use of flash features. From the two tables, 5 responses were N/A; this was traced to IS.

Table 7. Grand Summary for Design Parameters

\begin{tabular}{|c|c|c|c|c|}
\hline S/N & Parameter & High & Low & N/A \\
\hline 1 & AIB & 10 & 5 & - \\
\hline 2 & PV & 11 & 4 & - \\
\hline 3 & IS & 3 & 6 & 5 \\
\hline 4 & LT & 13 & 1 & - \\
\hline 5 & NLP & 5 & 9 & - \\
\hline 6 & ML & 7 & 7 & - \\
\hline 7 & SA & 4 & 10 & - \\
\hline 8 & UA & 6 & 8 & - \\
\hline 9 & CU & 8 & 6 & - \\
\hline 10 & SB & 9 & 5 & - \\
\hline 11 & PD & 4 & 10 & - \\
\hline 12 & CT & 8 & 6 & - \\
\hline 13 & UF & 0 & 14 & - \\
\hline & TOTAL & 88 & 91 & 5 \\
\hline
\end{tabular}

The rationale for this choice at certain websites was the fact that LEEGA basically offer services as opposed to the sale of products, which is usually the case for shopping websites.

On our instructions regarding the number of links that constituted high/low context cultures, the rule of thumb is to keep the links at 100 per website; this was taken from Google sources. Cutts [37] much later in a blog post quoted the Google guidelines saying, "Keep the links on a given page to a reasonable number (fewer than 100)". This is traceable to reasons such as bandwidth utilization, fitness and processing limits. The consequences according to SEO and Matt, is that "the more links a page has, the less internal PageRank each of those links passes" and in Matt's words, “....at any rate, you're dividing the PageRank of that page between hundreds of links, so each link is only going to pass along a minuscule amount of PageRank anyway". While reviewing the number of links used on the sites, we discovered that the NA site has the highest number of links (on a total) i.e. 238 as well as the highest number of internal links i.e. 210. This is followed by the FRSC site with 186 total links. On internal links, NA is followed by the ICPC site which has 148 links. For external links, the FRSC site has the highest number i.e. 43, and this is followed closely by the NA site which has 28. While the DIA site has only one external link, the NDLEA site has no external link.

\section{5- Conclusions}

In this study, we employed the online survey approach which is aimed at evaluating the cultural anthropology/profile of law enforcement agencies in Nigeria. Interestingly, the derived conclusions confirms the uniqueness of the efforts expanded in this research. This is because the majority of websites' usability studies in HCI and informatics make use of financial institution and shopping websites. Questionnaires that represent the features of the above-mentioned proponents of cultural models were distributed to a group of experts and their answers were collected, analyzed and presented in the tables above. The results show that for law enforcement agencies in Nigeria, the culture context profile is predominantly low (91 out of 182 expected statuses on Table 6 and 91 out of 184 expected statuses on Table 7). This is against the high context results, which are 86 out of 182 expected statuses on Table 6 and 88 out of 184 expected statuses on Table 7.

It is noteworthy to reiterate here that the margin in between (cumulative high and low choices/responses) is not wide. First, this result is in contradiction to Umeh, et al. [13], wherein the context culture is high (42 out of 77 expected statuses) for institutional websites in Nigeria. Additionally, our result contradicts the conclusion drawn 
by Köszegi, et al. [38], which goes thus, "If countries from Africa were to be positioned on the diagram (Fig. 17), they would reside somewhere within the red circle". Although this diagram performed a global evaluation of cultural dimensions of websites from several nationalities, the bias is on communication patterns. More so, it represents the first attempt to situate African nations in a culture context continuum.

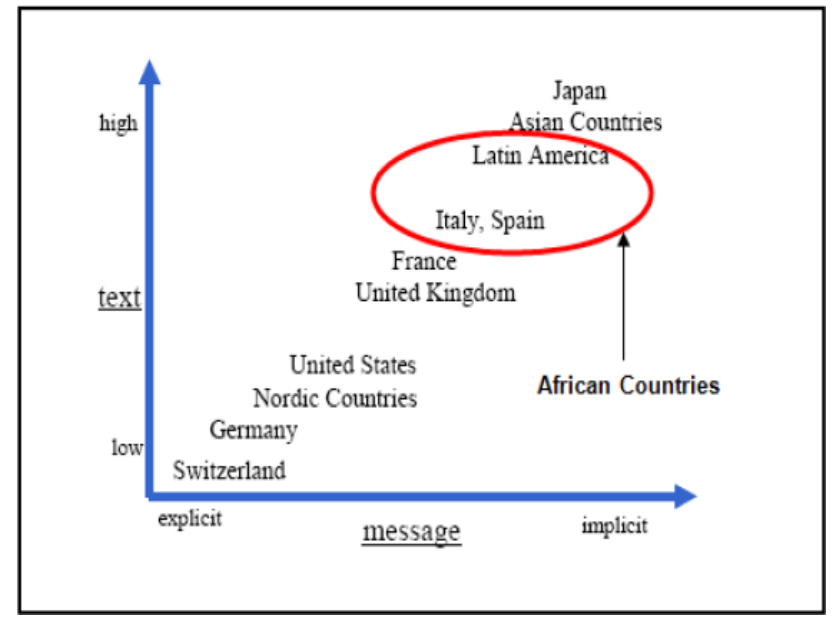

Fig. 17. Communication Patterns of Different Countries [38]

If we are to use Fig. 17, considering the direction of our study and its results, it would be wrong to situate Africa within the red circle (i.e. Latin America and Italy, Spain). The position of Africa would go lower on the continuum; within United Kingdom and Germany (Fig. 18).

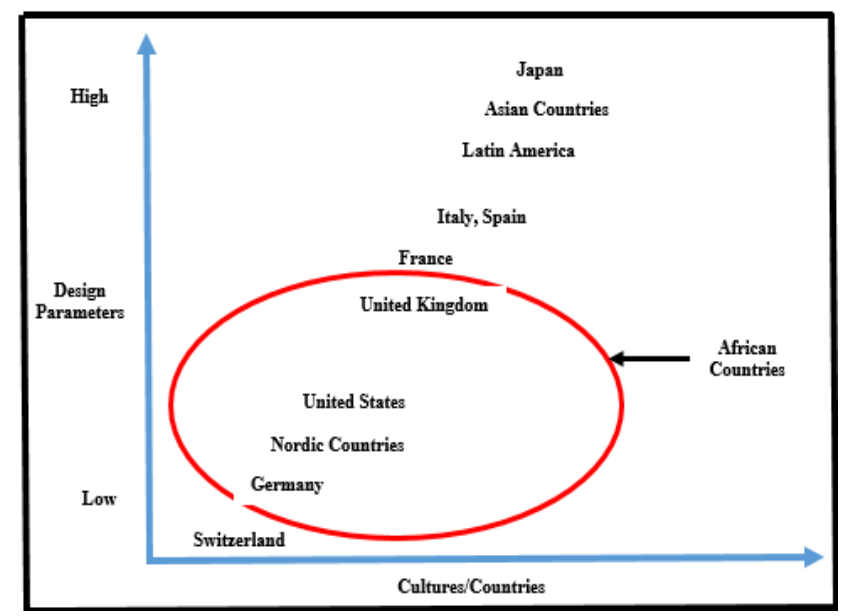

Fig. 18. Proposed Culture Contexts Continuum involving Africa
Considering Fig. 2 above alongside the aim of our study herein, Nigeria (Africa) would also come down to fall within French Canadian and Scandinavian (for the diagram on the left hand side) and within Latin and Scandinavian (for the diagram on the right hand side). However, since all these are speculations with little proof (except perhaps our study), there is need for a holistic study on the cultural dimensions of African nations. This would properly place Africa in any of the listed continuums. On the other hand, we noticed that none of the LEEGA websites used an indigenous language, even though Nigeria is a country with several indigenous languages. This is quite pitiable if one considers websites from Uzbekistan, China, Germany etc. Most times these sites are first displayed in their national language but with the help of an embedded language translator the visitor can use another language he/she feels comfortable in. And as Gygi and Spyridakis [7] puts it, therein, "the national language becomes a cultural marker". For a multilingual nation like Nigeria, using one national language might be a problem, which is why most websites use English - Nigeria's official language. Consequently, website developers can add the language translating capability for the three major languages in Nigeria i.e. Igbo, Hausa and Yoruba.

In the future, we hope to further investigate the cultural anthropology of websites designed for Africans using the design guidelines developed by Alexander, et al. $[12,21]$ as well as the Hofstede cultural dimension. The current study can also be extended by evaluating the accessibility and usability of websites owned by law-enforcement agencies in Nigeria.

\section{Acknowledgments}

We acknowledge the experts (web developers) scattered across the various regions of Nigeria for bringing out time from their busy schedules to attend to our questionnaires. The success of the study was largely because of their efforts. Additionally, we thank the anonymous reviewers that painstakingly ensured the accuracy of our work. 


\section{References}

[1] E. Wurtz, "Intercultural communication on web sites: A cross-cultural analysis of web sites from high-context cultures and low-context cultures", J. of ComputerMediated Communication, vol. 11, 2006, pp. 274-299.

[2] E. T Hall, The Silent Language, New York: Doubleday. 1976.

[3] G. Hofstede, Culture's consequences: International Differences in Work-Related Values. UK: Sage, 1984.

[4] D. Morley and K. Robins, Spaces of Identity: Global Media, Electronic Landscapes and Cultural Boundaries. US: Routledge, 1995.

[5] M. D. Myers, and F. B. Tan, "Beyond models of national culture in information systems research", Journal of Global Information Management, vol. 10, no. 2, pp. 23-56, 2002.

[6] L. Thorlacius, "Visuel Kommunikation pa Web sites," Ph.D. dissertation, Roskilde Universite, 2002.

[7] K. F. Gygi, and J. H. Spyridakis, "Developing a cultural model to support web site localization: a case study of Uzbek school websites," in Annual Conference Society for Technical Communication, vol. 54, 2007, pp. 1-20.

[8] A. Yeratziotis, and D. Greunen, "E-government - putting service at your fingertips," in IST-Africa 2009 Conference \& Exhibition, 2009, pp. 1-15.

[9] M. Herselman, and D. Greunen, "Global survey on culture differences and context in using e-government systems: a pilot study," in Second International ICST Conference, AFRICOM, 2010, pp. 46-68.

[10] R. Vatrapu, and M. A. Pérez-Quiñones, "Culture and international usability testing: The effects of culture in structured interviews", Journal of Usability Studies, vol. 1, no. 4, pp.156-170, 2006.

[11] F. T. Moura, N. Singh and W. Chun, "The influence of culture in website design and users' perceptions: Three systematic reviews," Journal of Electronic Commerce Research, vol. 17, no. 4, pp. 312-339, 2016.

[12] R. Alexander, D. Murray, and N. Thompson, "Crosscultural web design guidelines," W4A 2017, 2017, pp. 1-16.

[13] I. Umeh and C. H. Nwokoye, "Culture Context Profiles: A Case of Institutional Websites in Nigeria", Global Journal of Computer Science and Technology: G Interdisciplinary, vol. 17, pp. 1-17, 2017.

[14] I. O. Oyefolahan, A. A. Sule, S. A. Adepoju, and F. Babakano, "Keeping with the global trends: An evaluation of accessibility and usability of Nigerian banks website," $I$. J. Information Engineering and Electronic Business, vol. 2, pp. 44-53, 2019.

[15] SEO, Assessed on: July 24, 2020. [Online]. Available from https://seositecheckup.com/seo-audit/flash-test/

[16] Smallseotools, Assessed on: Aug 19, 2020. [Online]. Available from https://smallseotools.com/website-linkanalyzer-tool/

[17] J. Ouellet, J. Kang and A. Girouard, "Cultural and linguistic variables in usability testing: A Canadian evaluation of international students," Journal of Usability Studies, vol. 16, pp. 121-147, 2021.

[18] C. Sik-Lanyi and E. Orbán-Mihálykó, "Analyses of websites was done for healthcare in European countries," Arabian Journal for Science and Engineering, vol. 44, pp. 9171-9190, 2019.
[19] Z. Nong and S. M. Gainsbury, "Website design features: exploring how social cues present in the online environment may impact risk taking," Human behavior and emerging technologies, vol. 2, no. 1, pp. 1-35, 2019.

[20] N. Al-Shammari, "E-Commerce in Saudi Arabia: characteristics of a trustworthy usable e-commerce websites," International Journal of Information Science, vol. 9, pp. 6-15, 2019.

[21] R. Alexander, N. Thompson and D. Murray, "Towards cultural translation of websites: a large-scale study of Australian, Chinese, and Saudi Arabian design preferences," Behaviour \& Information Technology, vol. 36, pp. 351 363, 2017.

[22] L. Al-Omairi, H. Al-Samarraie, A. I. Alzahrani and N. Alalwan, "Students' intention to adopt e-government learning services: a developing country perspective," Library Hi Tech, vol. 39, pp. 308-334, 2020.

[23] Nigeria Airforce, January 2020. Assessed on: June 20, 2021. [Online]. Available from https://airforce.mil.ng/

[24] Nigeria Navy, March 2020. Assessed on: June 20, 2021. [Online]. Available from http://www.navy.mil.ng/

[25] Nigeria Army, January 2019. Assessed on: June 20, 2021. [Online]. Available from https://www.army.mil.ng/

[26] Nigeria Police Force, January 2019. Assessed on: June 20, 2021. [Online]. Available from https://www.npf.gov.ng/

[27] Nigeria Prisons Service, January 2019. Assessed on: May 5, 2019. [Online]. Available from http://www.prisons.gov.ng/

[28] Nigeria Immigration Service, January 2019. Assessed on: June 20, 2021. [Online]. Available from https://immigration.gov.ng/

[29] Nigeria Security and Civil Defense Corps, January 2019. Assessed on: June 20, 2021. [Online]. Available from http://nscdc.gov.ng/

[30] Nigeria Customs Service, January 2019. Assessed on: June 20, 2021. [Online]. Available from https://www.customs.gov.ng/

[31] Federal Road Safety Corps, January 2019. Assessed on: June 20, 2021. [Online]. Available from https://frsc.gov.ng/

[32] Federal Fire Service, January 2019. Assessed on: June 20, 2021. [Online]. Available from http://fedfire.gov.ng/

[33] Defense Intelligence Agency, January 2019. Assessed on: June 20, 2021. [Online]. Available from http://www.dia.gov.ng/

[34] National Drug Law Enforcement Agency, January 2019. Assessed on: June 20, 2021. [Online]. Available from https://ndlea.gov.ng/

[35] Independent Corrupt Practices and Other Related Offences Commission, January 2019. Assessed on: June 20, 2021. [Online]. Available from http://icpc.gov.ng/

[36] Economic and Financial Crimes Commission, January 2020. Assessed on: June 20, 2021. [Online]. Available from https://efccnigeria.org/efcc/

[37] M. Cutts, How many links per page. Gadgets, Google, and SEO, 2009, January 2020. Assessed on: January 30, 2020. [Online]. Available from https://www.mattcutts.com/blog/how-many-links-per-page/

[38] S. Köszegi, R. Vetschera, and G. E. Kersten, "National cultural differences in the use and perception of Internetbased NSS: Does high or low context matter?" Assessed on: January 30, 2020. [Online]. Available from interneg.concordia.ca/views/bodyfiles/paper/2003/09.pdf 
ChukwuNonso H. Nwokoye obtained a BSc and PhD degrees in Computer Science. He is two-time ACM SIGCHI Gary Marsden Student Award recipient. His interests include simulation and modeling of complex systems, semantic web, agent-based modeling, wireless sensor networks and network security, human computer interaction (social computing, computer supported cooperative work) and computer mediated communication. $\mathrm{He}$ is currently on evaluating the accessibility and usability of websites owned by government agencies in other African countries.

Njideka N. Mbeledogu is a Senior Lecturer at the Department of Computer Science, Nnamdi Azikiwe University, Awka, Nigeria. She holds Bachelor of Science (BSc), Master of Science (MSc) and PhD degrees in Computer Science. She is a member of the Computer Professional of Nigeria (CPN) and the Nigerian Computer Society (NCS). Her interests include network security, neural networks, semantic web, human computer interaction and fuzzy logic

Chikwe Umeugoji obtained a BSc in Computer Science from Nnamdi Azikiwe University, Awka, Nigeria. She is currently a postgraduate student at the same institution, wherein she is currently working on design and implementation of mobile and desktop applications for diverse disciplines. Her other disciplines include network security, neural networks, semantic web, human computer interaction and fuzzy logic. 